\title{
Design and implement a new secure prototype structure of e-commerce system
}

\author{
Farah Tawfiq Abdul Hussien, Abdul Monem S. Rahma, Hala Bahjat Abdul Wahab \\ Department of Computer Science, University of Technology, Baghdad, Iraq
}

\begin{tabular}{|c|c|}
\hline Article Info & ABSTRACT \\
\hline Article history: & The huge development of internet technologies and the widespread of \\
\hline Received Mar 15, 2021 & $\begin{array}{l}\text { modern and advanced devices lead to an increase in the size and diversity of } \\
\text { e-commerce system development. These developments lead to an increase in }\end{array}$ \\
\hline Revised Jul 14, 2021 & the number of people that navigate these sites asking for their services and \\
\hline Accepted Aug 2, 2021 & $\begin{array}{l}\text { products. Which leads to increased competition in this field. Moreover, the } \\
\text { expansion in the size of currency traded makes transaction protection an }\end{array}$ \\
\hline Keywords: & $\begin{array}{l}\text { essential issue in this field. Providing security for each online client } \\
\text { especially for a huge number of clients at the same time, causing an overload }\end{array}$ \\
\hline Agent & on the system server. This problem may lead to server deadlock, especially \\
\hline Deadlock & and \\
\hline E-commerce classification & software. This agent will play the role of broker between the clients and the \\
\hline E-commerce system & electronic marketplace. This is done by providing security inside the client \\
\hline management & device and converting the client's order into a special form which is called a \\
\hline Performance & record form to be sent to the commercial website. Experimental results \\
\hline Secure e-commerce structure & $\begin{array}{l}\text { showed that this method increase system performance in terms of page } \\
\text { loading time, transaction processing and improves the utilization of system } \\
\text { resources. }\end{array}$ \\
\hline
\end{tabular}

This is an open access article under the CC BY-SA license.

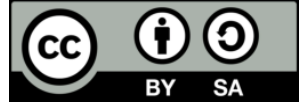

\section{Corresponding Author:}

Farah Tawfiq Abdul Hussien

Department of Computer Science, University of Technology

52 street, University of Technology, Baghdad, Iraq

Email: Farah.T.Alhilo@uotechnology.edu.iq

\section{INTRODUCTION}

The web has been moving towards a real economy and a modern business frontier since 1997. Many corporations have, therefore, changed to the online sector. However, since there are many rivals out there, not all e-commerce websites can succeed. Since e-commerce websites are all about attracting and retaining customers, ensuring that consumers have a positive experience during the entire process is crucial [1]. According to [2], within 2 months, 80 percent of highly satisfied consumers will come back to buy products again and 90 percent of them will recommend them to others. $87 \%$ of unsatisfied consumers, however, would never come back without any concerns, if they experience difficulties in achieving their goals, such as finding information and finding items they want to purchase, they may simply leave the website. Poor design of e-commerce websites would result in productivity and income losses, as observed by [3]. Hence, having a guideline for designing a good e-commerce website would be beneficial.

The registration of all trade is another contribution of e-commerce to national and global economies. The informal economy, one of the big problems facing developing countries, has been removed and significant increases in tax revenues have been achieved [4], [5]. The e-commerce amount is reached $\$ 1$ trillion 700 billion in 2015, \$2 trillion in 2016, and $\$ 2$ trillion 500 billion in 2018, according to the findings of the global research firm, e-marketer [6]. In the world of commerce, these tremendous developments are 
called the new economy. The economic effects of electronic trading contribute to an acceleration of the process of transformation from a conventional view of trade to a modern world economy [7], [8]. The global B2C e-commerce market size in 2019 was estimated at USD 3.35 trillion and is forecast to rise from 2020 to 2027 at a compound annual growth rate (CAGR) of 7.9 percent. Due to rising digital dependence and the convenience of shopping on online platforms, the market is expected to witness high growth over the forecast period [9], [10].

This research aims to satisfy clients to ensure their return. This is done by increasing system performance. This research shows two issues that may reduce system performance security and deadlock. These problems can be solved by using an agent system to provide security for clients and prevent the problem of deadlock without affecting the speed of the e-commerce website.

\section{GENERAL E-COMMERCE DESCRIPTION}

E-commerce represents not only the ability to purchase and sell goods and services via a digital medium such as the internet but also the ability to automate the entire sales, purchase, and payment process also provide a simple recommendation system for customers to facilitate for the client to find the required products. The proposed system aims to automate all the processes and transactions among three parties' clients, e-commerce websites, and e-bank websites [4], [10]. The foreground and background functions are shown in the following Figures 1 and 2.

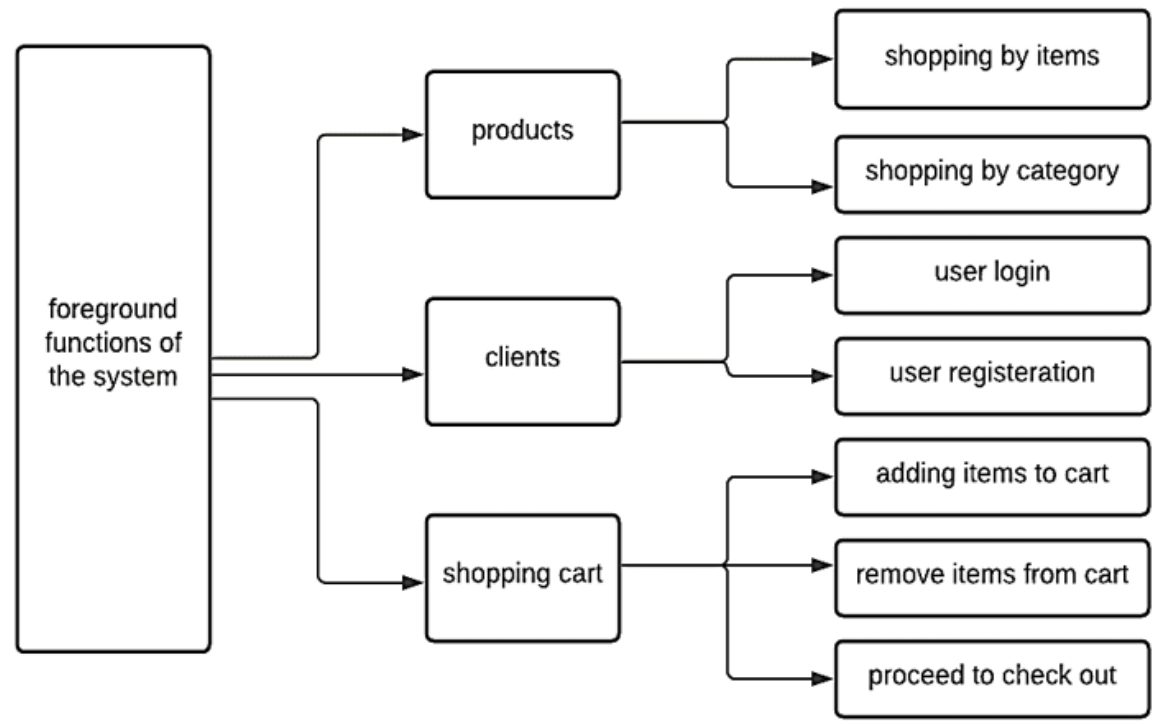

Figure 1. Foreground functions of the system [4]

\subsection{E-commerce system design classifications}

E-commerce system design in its development has passed through several stages affected by client's requirements, internet development, and technology development (software and hardware), therefore, and according to the design of the related works presented previously e-commerce systems can be classified into the following types:

- The simplest design consists of two entities the e-shop and clients in which clients shopping and making orders using phones or message and the pay at product delivery time. Anybody can buy from such an e-shop system so there is no way to authenticate client identity because there is no database for client's information, there is the only database for products. In this type of system, there is no financial assurance for e-shop because the client can refuse to receive the product or even deny the order which means returning the goods to the e-market, which causes financial losses to the e-market [11]. These types can be represented as in the Figure 3. There is not any type of security in this type anybody can spoofing or intruding the connection regardless of its type.

- The second type consists database for clients so that the e-shop allow only authentic clients to buy from the system and there will be the ability to retrieve client information in case of any problems also this type of e-shop provides different payment options credit cards, visa card, or any other available means according to the country. In this type there will be financial assurance for the e-commerce system but not 
for the client because in some cases after paying by the clients the products may not deliver for the client for many reasons so the clients may not be able to recover his money [12]. This type of system can be represented as in the following Figure 4.

In the previous designs, the bank has no serious rule so this paper suggests a new design that takes into consideration the e-bank design and its rule in the communications among all entities so now the system has three entities as following [13], [14]: i) e-commerce system, ii) e-bank system, and iii) client. So here there will be a connection between the e-bank and the e-commerce and communication between e-bank and client to confirm the financial transaction and provide financial assurance for all parties system design represented in the following Figure 5.

All the previous designs focus on the following things. The method of products display: i) Profits and ii) Reducing losses due to damage to goods during transportation, or the customer's refusal to receive the goods, or even his refusal to pay. So, the proposed system tries to solve some gaps that the previous designs overlooked which include speed, security, and performance.

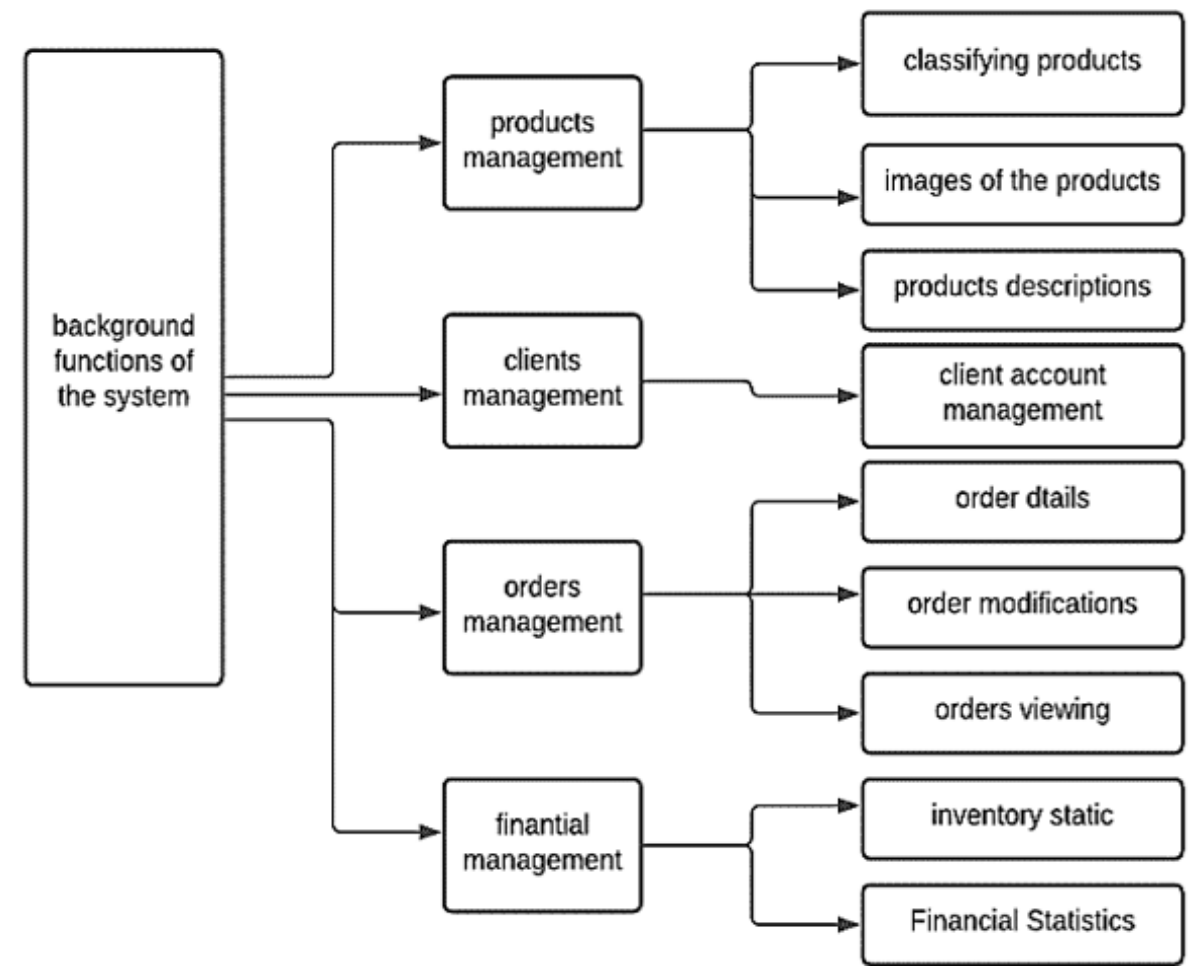

Figure 2. Background functions of the system [4]

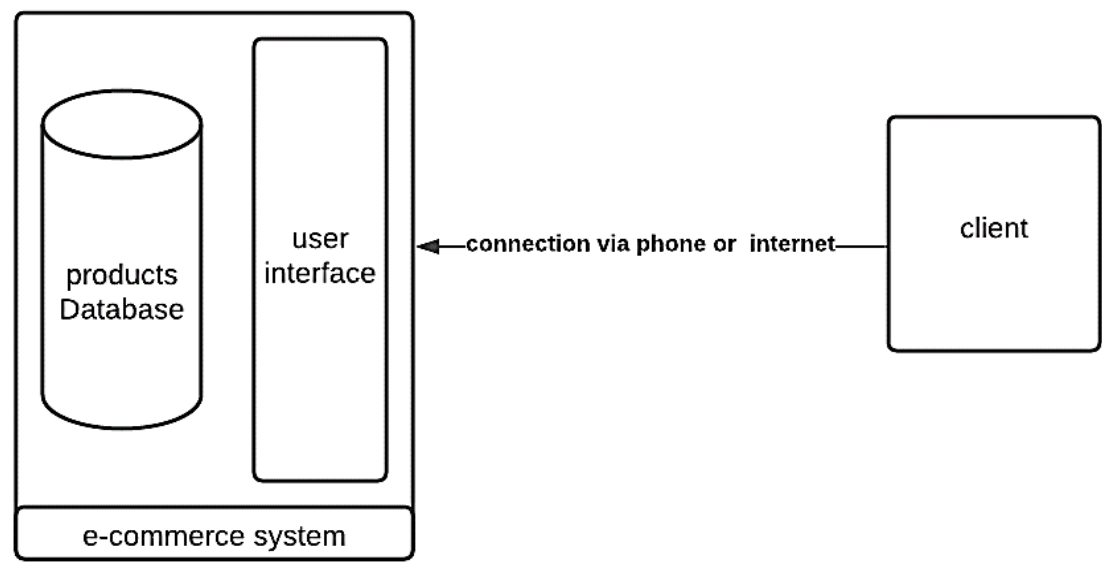

Figure 3. Simplest e-commerce system design 


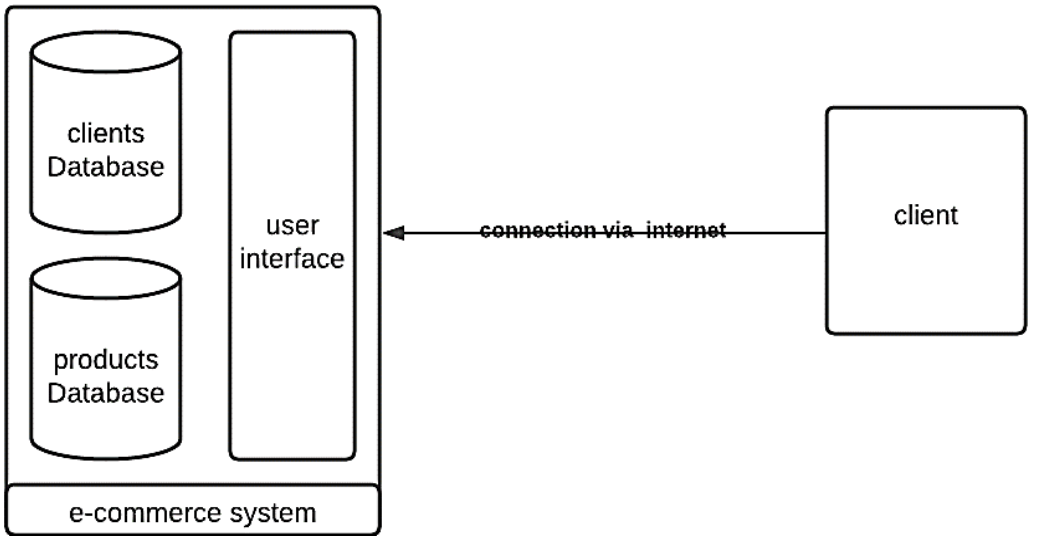

Figure 4. Developed design from the simplest one

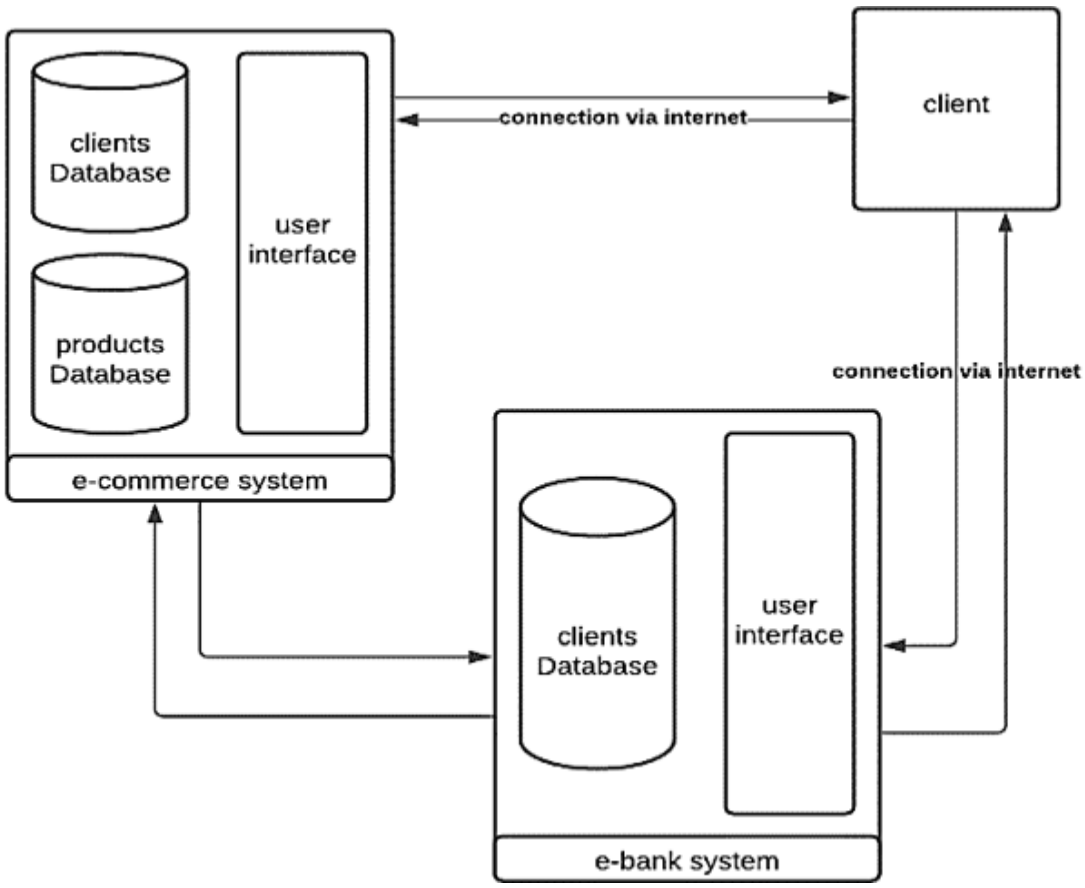

Figure 5. Most common e-commerce system design

\section{RELATED WORKS}

Due to the importance of the e-commerce system, several papers presented different designs using different tools to improve performance and solve some weaknesses. Fadiya et al. [15] proposed a paper to create an e-commerce shop, providing the consumer with an e-commerce platform that is used to locate the store and its locations online as part of a cloud domain. ASP.NET is used as the technology to actualize this as a web application. VB.NET was the language used to build this application. To communicate with the database, ASP.NET utilizes ADO.NET. The back-end database used was MSSQL. A password has been added to the database so that only the administrator who knows the password can access it. As the customer login page can only be limited to its facilities, a different measure of access level is required, but the administrator would have overall access to the database. Performance is calculated by the time of any function, varying from 2 to 5 seconds depending on the function.

Sharminakter [16] demonstrated different trade and trade restrictions in general and e-commerce in particular. It established a virtual marketplace with new partnerships between firms and customers. There are a variety of critical elements of the e-commerce system, a database (MySQL), a website for e-commerce (developed by PHP), a security system (secure socket layer) and a payment portal (non-bank payment service was introduced to electronic commerce: PayPal). The paper aimed to create an e-commerce portal that allows 
products buyer's a single one-stop marketplace or home to purchase their products. Wei and Zhang [17] indicated that one secret client mode after WEB creation is the B/S configuration (Browser/Server). To incorporate the central component of device feature realization with the server, this form of network structure mode unifies the WEB browser as the client-side. In the B/S paradigm, the client only requires one browser and the browser communicates with database data via the web server. The system implements the online shopping system network through the model, display, and controller (MVC) architecture. Customers can recognize at any moment the related product data, and they can provide bulk commodity data. Technologies used in system development, including the architecture of Java and JSP and spring.

Malgwi and Mathias [18] suggested a framework to create a forum and put together sellers and customers to connect and do business. The idea was made to build a technology that would include the most appropriate and quickest way to establish an online exchange, known as e-commerce. A framework built utilizing UML software and then added to the localhost server (XAMPP).at using PHP, jQuery, MYSQL, CSS, and HTML5 whenever individuals will create a bid for products. Three-tier structural architecture, namely the client tier, the application server tier, and the database tier, is the approach used in evaluating and designing computing tools. Alsultani et al. [19] proposed a specification of an online customer/server architecture e-commerce web application that trades variant goods to consumers, with payment choices either on arrival or instantly. They aim to use HTML, JSP, and qualitative analysis in the context of an exploratory case study to design e-commerce implementation. The role is selected by the web browser. The technologies introduced include Adobe Dreamweaver, relational databases, and several programming languages such as HTML, CSS, Java, JavaScript, and PHP, and credit card is the payment form implemented.

The paper presented by Yunus and Masum [20] traverses all the necessities to build a proper e-commerce framework with accessible and free tools and technologies for development. The paper focused mainly on the design and implementation of a B2C e-commerce system to enforce the growth of local businesses nationally and internationally, this paper showed context analysis of an e-commerce system that involved stakeholders, their needs, feasibility study of the rapid development of the e-commerce system and, most significantly, the overall interaction between consumers and customers. The development tool here is content management system (CMS), which is used for the rapid development of the Django architecturebased e-commerce system. For security purposes, a verification code will be sent to the customer's mobile number after registration to confirm that the user is not fraudulent, separate admin and consumer website were only approved IP's can connect to the admin server that prevents any form of intrusion on that server.

\section{EVALUATING CRITERIA}

According to software engineering rules, each software system should be evaluated depending on certain features. For an e-commerce system, these features involve the following:

\subsection{Usability testing}

This is where a website is measured in terms of how convenient it is to access a single piece of data. It is also possible to use usability tests to assess whether a new feature on a website is easy to understand and effective to use. Companies also aim to restrict a set number such as three to the number of clicks needed to reach a certain piece of information. To determine, for example, if more than three clicks are needed to access a product or service, a group of test users is then asked to navigate through the web [21], [22].

\subsection{Security}

Network protection and transaction security are the two most important architecture problems surrounding security in e-commerce applications [23]:

- Network security: Data travels across numerous media that are not controlled by the management of the e-commerce platform. This condition raises some of the safety and security problems of the application of e-commerce. Designers must make sure that data can pass securely, despite this handicap, with a minimal chance of being interrupted [24]. It is essential to identify data when it is required and make it accessible when it is not essential. For instance, it may not be important to secure the transmission of shopping cart information while shopping. On the other side, as far as possible, all transactions holding clients' data or payment data should be safe [25]

- Transaction security: The SSL protocol's key concern is to make sure that what is sent is what has been submitted. Also, there is no confirmation that the client or organization is who it claims to be. Which is alluded to as the authentication problem [26], [27]. In addition, in an e-commerce agreement, one of the parties may dispute being an actor. This is the issue of non-reputation. To deter any unauthorized party from accessing this content, the organization in charge of the e-commerce platform should take reasonable measures. This is the dilemma with secrecy [28]. To guarantee the performance of the 
organization operating the e-commerce application, all these concerns should be resolved by the designers (authentication, non-repudiation, and confidentiality). The solutions for these problems include the use of modern cryptographic methods [29]. However, the challenge is that many designers of e-commerce software neglect or refuse to adequately treat these primary non-functional criteria because of their lack of expertise in designing the reliability characteristics of the e-commerce program [25], [30]

\subsection{Tools and languages}

One of the early decisions of high-level programming is that programmers need to determine which languages/tools can be employed to create their apps. Applications for e-commerce typically include an extensive variety of programming languages or instruments. Some of the most common are Perl, Java, ASP.NET, JavaScript, PHP, and HTML. The preference of one language over another is complicated since potential developments have to be expected by the designer. Moreover, modern languages are increasingly evolving, and no one can easily guess their survival, success, and adoption. In comparison, certain modern languages, such as ASP.NET/VB.NET, are related to a certain operating system (Windows operating system) and do not operate on other systems [31].

\subsection{Database}

By design, e-commerce apps are network-intensive, complex, distributed and client-server apps [32]. For storage records, relational databases are almost uniformly used. The most popular DBMS are RDBMS, such as IBM DB2, Sybase, Microsoft structured query language (SQL), or MySQL. Data manipulation is achieved with SQL [33]. In some common e-commerce systems, the non-relational DB paradigm, like NoSQL, is increasingly acquiring popularity as the underlying data storage framework. Help for interoperability between software and sources of data is a huge challenge this is because a particular interface and value proposition comes with each application/data source. Any workarounds for NoSQL functionality have arisen to operate like the traditional SQL-based relational database [34], [35].

\subsection{Interface design issues and navigation}

For user interface programmers, the user interface is not Web applications and the navigation between windows or forms is not a big problem since there are well-known architecture patterns [36] and can be used as guides to create applications effectively. Web apps, particularly e-commerce apps, have no too much previous skill to draw on [37]-[39]. Several surveys [40], [41] A reflection of patterns before 2000 is presented here. Since then, certain innovations have vanished and other new ones have arisen, leaving missing or obsolete portions of their studies. Several new observational research, however, [42]-[46]. Comply with their assumptions. For the navigation and the user interface design, a range of simple principles (page- load, navigation performance, business content, protection, and marketing/clients focusing) specific to the application of e-commerce are important. Web pages with a fair speed of page-loading must be open to consumers around the world. E-commerce retailers aim to provide their clients with more important, more customized, and more persuasive shopping experiences. For example, consumers want relevant, certain, and customized results of search generated in milliseconds, irrespective of the geographical position or computer [42]. Reaction times can be shortened by a factor of around 2 to 5 seconds by using appropriate types and strategies for the design and content of pages. The computer servers may dramatically increase the speed of page distribution by utilizing advanced content delivery networks or local bandwidth increasing [47].

\section{THE PROPOSED SYSTEM}

This research aims to build a prototype model that represents the e-commerce environment involving the three main entities (client, marketplace, and e-bank). The Important issue in the e-commerce system is protecting transactions with clients to prevent information stolen, altering or faking. Protecting each online client will cause overload on the system server especially when a huge number of clients navigating the website at the same time. This problem can be solved by generating and customizing agents for each client's device. The agent will reduce the load over the server by taking over the responsibilities of the transaction. The transaction involves, generating a form record for each order, encrypting information, and sending the order to the website. These orders will be saved into the D.B. cloud to prevent losing them in rush time. Also, the agent provides authorization to identify the client's identity because each agent has a unique identifier to distinguish between them. For each client, there will be a record containing user information, agent id one of this information. Each record containing client's order will be encrypted using an encryption algorithm and encryption key, agent id will be appended to the beginning of each packet that is sent to the e-commerce website. The agent Id at the website will be used to retrieve the customer encryption key which is stored with client information at the website database. On the other hand, the e-bank will customize an agent for each client to manage financial affairs and protecting payment information. 
This prototype model provides protection for the three entities of the e-commerce environment and reduces overload on the system server, increases system performance, and protects transactions. Furthermore, all the identities of the clients will be verified utilizing agent Id. Figure 6 represents system dataflow diagram, it contains the following items:

- Order: it is a record form that is generated by the agent. It contains the following information that represents the client's purchase details: client-ID, agent-ID, product-ID, quantity, address, date, and time.

- Bills: consist list of order details, payment amount, and payment method to be checked by the client to add or delete items and select payment method.

- Confirm: when the client choosing a payment method it represents ad confirmation to complete the purchase process

- Asking for payment: sending bills containing client id according to a payment method to the e-bank.

- Notification: is sent to the client containing the payment amount to whom to pay.

- Transfer money to the website account.

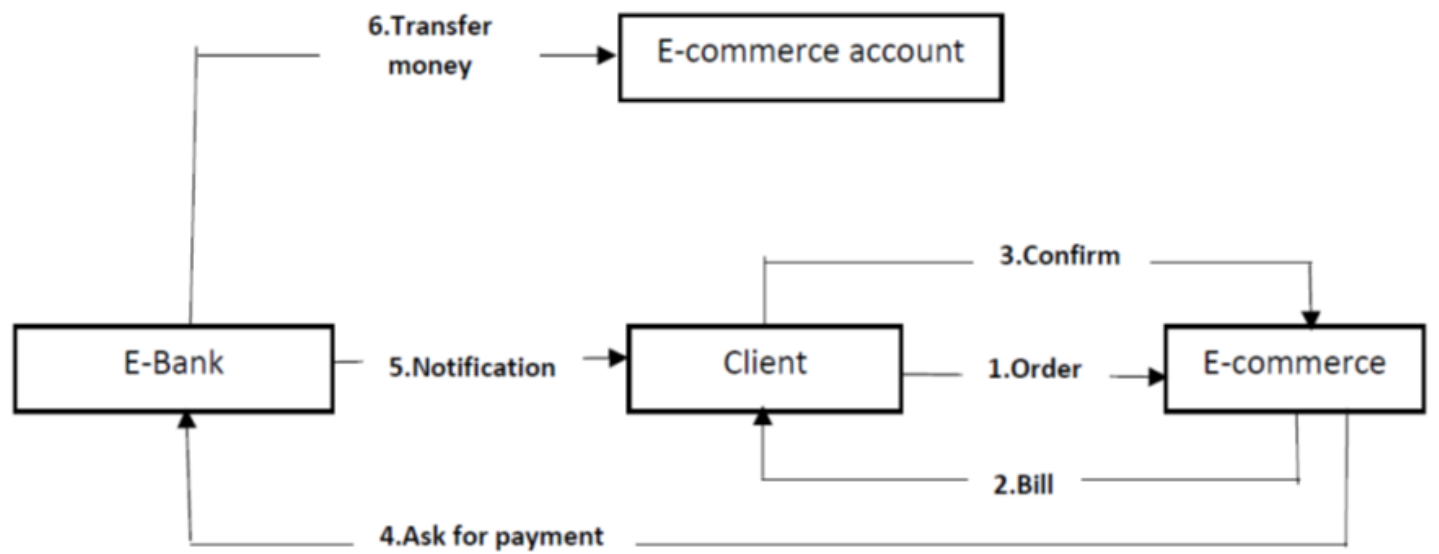

Figure 6. Data flow diagram between the main entities of the e-commerce system environment

The proposed system aims to build an integrated system for the electronic market, the electronic bank, and the customer takes the three parties to the commercial process into consideration and treats the system as a case study to investigate and show the gaps that represent weaknesses of the system and reach solutions for them and from these gaps:

- Security, as the messages are open and any intruder can see their content, and some messages include payment and account information, so it is more important than others as tampering with them causes financial loss-so adequate protection for this type of information must be provided by an agent who manages. The messaging process and supervises the process of receiving and sending data and protecting it using one of the types of encryption.

- How to save business process information. There is no doubt that there are many types of databases, but it is possible to take advantage of the cloud services to save data, especially since the cloud has additional security features, and one of these examples is noSql, which allows storing data in a different format (no commitment required a unified pattern for the type and method of storing data for example, Google databases (Firebase), as it provides a free service using Spark's plan for a certain volume of transactions, as it provides the advantage of saving data on the cloud, and thus the data is secure in the event that datasaving devices are exposed to an accident or destruction, as it provides security options as desired, whether by specifying the email, password, or phone, and other options to determine who are authorized to enter and view the stored information, as firebase was used to save information about customers and transactions information by proposing a simple design for the bank's website to log in or create a registry and thus allow customers by creating an account and depositing money for the purpose of making purchases via the internet.

- Speed in transactions among the three entities.

- Provide recommendations for the clients to facilitate finding the required products

According to [21], [25] the security aspect is a very important consideration and after analyzing the related works mentioned previously and the proposed system it appears that these systems are weak from the security point of view and especially the clients because he does not has enough knowledge about security 
nor ability to provide it, therefore, a new design is suggested that provide security and increase efficiency for the e-commerce system by depending on an agent in the middle to manage communications among the three entities of the e-commerce system and using coding that reduce efforts and time of communications so the proposed system design can be presented by the following Figure 7 .

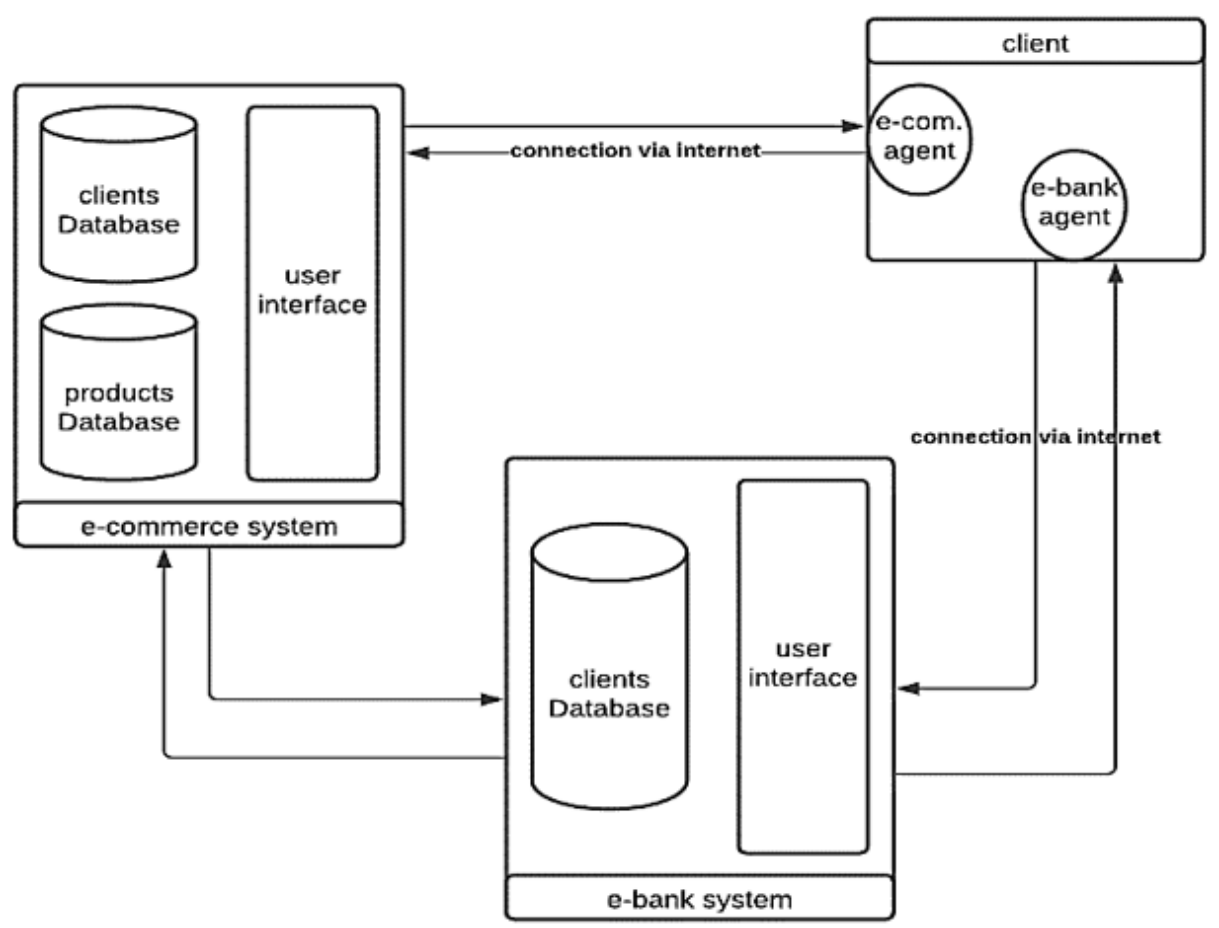

Figure 7. Proposed system design

\subsection{Proposed transaction scenario}

The communication between the three entities (client, e-commerce website, and e-bank) consists of several steps as described in the algorithm 1:

Algorithm 1: Transaction processing

Input: user order

Output: payment bill

Start

Step 1: User sign in to buy

Step 2: Add products to the cart

Step 3: E-shop ask for order confirmation

Step 4: Provide clients with the bill to pay (provided by customer information)

Step 5: The customer agrees to the order and provides the web with his/her information to pay

Step 6: The e-shop contacts the e-bank for payment

Step 7: The e-bank informs the customer about the payment

Step 8: After completing the payment the bank will inform the e-shop and the client of the payment.

End.

\section{SYSTEM EVALUATION}

System evaluation is an important part of system validation because time and system resources are important features. Page loading time, system concurrency, and transaction processing speed are for system testing. Page loading time plays an important role in attracting clients, so reducing loading time attracts more client's experimental results shown in Figure 8 shown the improvements in the proposed system.

In the early testing phase, system load capacity is not well before optimization, and the number of system current connections is small this is solved by converting HTML to the static of Website, Figure 9 shows the system concurrency. Increasing transaction speed is another important feature in increasing 
performance because it means that increasing number of transactions will be processed fast which makes clients satisfy and ensure that he/she will come back again, Figure 10 shows the results after system improvements.

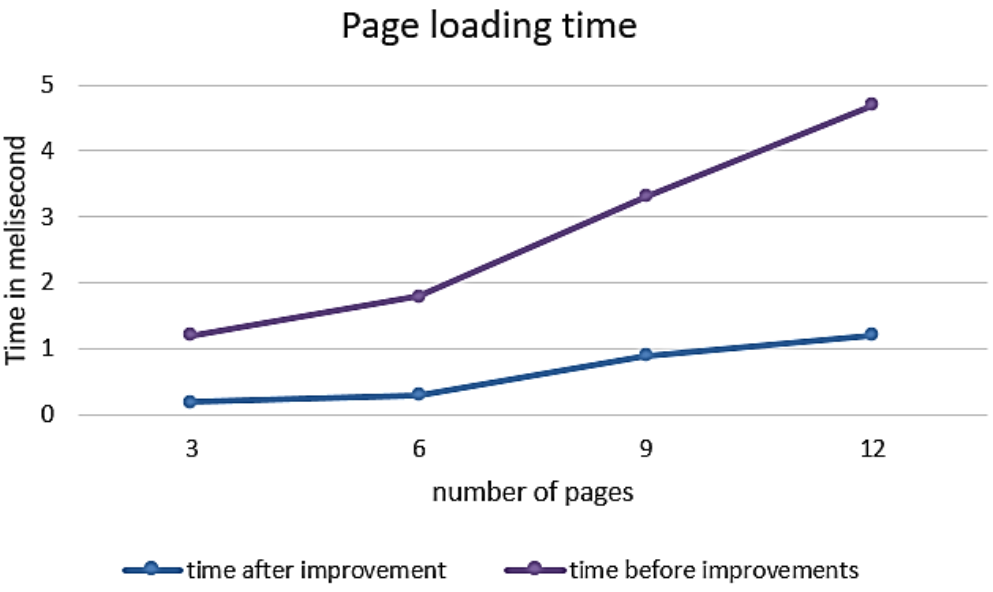

Figure 8. Time of pages load

\section{System Concurency}

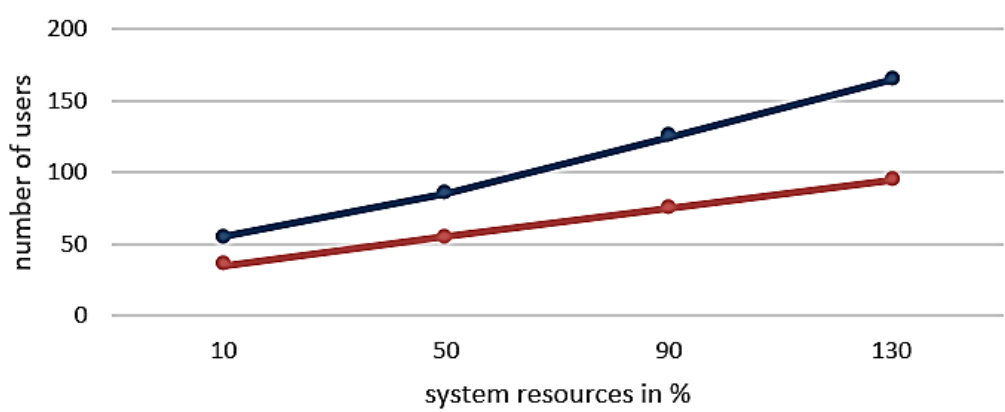

utilising system resources after improvements

$\Longrightarrow$ utilizing system resources before improvements

Figure 9. System concurrency

\section{Transaction processing speed}

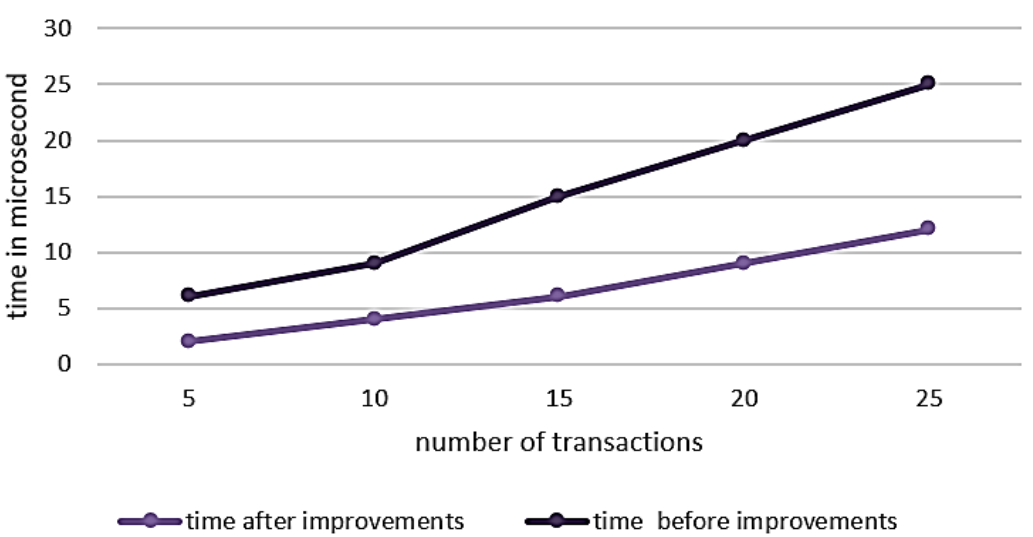

Figure 10. Transaction processing speed 


\section{RESULTS AND DISCUSSION}

The proposed system is compared with other systems according to several evaluation criteria mentioned previously Table 1 shown this comparison.

Table 1. Comparison between proposed system and other systems

\begin{tabular}{|c|c|c|}
\hline Criteria & Proposed system & Other systems \\
\hline Usability & $\begin{array}{l}\text { It is reflected by navigations speed experiments showed a high } \\
\text { speed in navigations between website pages }\end{array}$ & $\begin{array}{l}\text { Different from system to another depending } \\
\text { on system structure }\end{array}$ \\
\hline Technologies & $\begin{array}{l}\text { Used technology (python, flask, JS, Sqlite, NoSQL) made the } \\
\text { system compatible with different operating systems }\end{array}$ & $\begin{array}{l}\text { Some are compatible and some are not due to } \\
\text { used technologies }\end{array}$ \\
\hline Security & $\begin{array}{l}\text { Is provided by the language and the agent provide additional } \\
\text { security and facilitate the work on clients also provide a way to } \\
\text { verify the client identity }\end{array}$ & $\begin{array}{l}\text { Not specified except paper number (6) in } \\
\text { related works }\end{array}$ \\
\hline Agent & $\begin{array}{l}\text { Automate the transaction among the } 3 \text { entities and facilitate the } \\
\text { work for clients who had no background in dealing with } \\
\text { computers because the agent saves time and necessary information } \\
\text { so that the clients do not need to make extra efforts to handle work }\end{array}$ & Not used \\
\hline
\end{tabular}

\section{CONCLUSION}

Security is an important issue in the e-commerce system. Providing security for each online customer (especially for a huge number) at the same time may cause system deadlock, which reduces system performance. Using an agent to manage the purchase and provide security for each client on his device increases system performance. This is proved in experimental results by reducing the page loading time, transaction processing, and utilizing system resources. Agent solved the problem and increase performance which means satisfying clients that leads to financial gain.

\section{REFERENCES}

[1] A. Berglund and M. Svantenson, "Sustainable e-commerce how to integrate the dimensions of sustainability within the ecommerce sector," M. S. thesis, University of Gävle, Jun. 2018.

[2] Z. Baubonienè and G. Guleviciute, "E-commerce factors influence consumers' online shopping decision," Social Technologies, vol. 5, no. 1, pp. 74-81, 2015.

[3] M. A. Hassan Z. Shukur, and M. K. Hasan, “An efficient secure electronic payment system for e-commerce,” Computers MDPI, vol. 9, no. 6, pp 1-13, 2020, doi: 10.3390/computers9030066.

[4] J. Windsor. "B2C e-commerce market size, share and trends analysis report by type (B2C retailers, classifieds), by application (home décor \& electronics, clothing \& footwear) The region, And Segment Forecast." Market Publishers. https://pdf.marketpublishers.com/grand/b2c-e-commerce-market-analysis.pdf (accessed Feb. 16, 2020).

[5] M. V. Alderete, "Electronic commerce contribution to the SME performance in manufacturing firms: a structural equation model," Contaduría y Administración, vol. 64, no. 4, pp 1-24, 2019, doi: 10.22201/fca.24488410e.2019.1922

[6] R. Ciarniene and G. Stankeviciute, "Theoretical framework of e-business competitiveness," Procedia-Social and Behavioral Sciences, vol. 213, pp. 734-739, 2015, doi: 10.1016/j.sbspro.2015.11.528.

[7] Z. A. Alizai, H. Tahir, M. H. Murtaza, S. Tahir and K. Mcdonald-Maier, "Key-based cookie-less session management framework for application layer security," in IEEE Access, vol. 7, pp. 128544-128554, 2019, doi: 10.1109/ACCESS.2019.2940331.

[8] H. D. Tran, "From e-commerce to m-commerce," Journal of Textile Science and Fashion Technology, vol. 6, no. 1, pp. 1-2, 2020, doi: 10.33552/JTSFT.2020.06.000630.

[9] M. A. Chauhan, M. A. Babar, B. Benatallah, "Architecting cloud-enabled systems: a systematic survey of challenges and solutions," Software Practice and Experience, vol. 47, no. 4, pp. 599-644, 2017, doi: 10.1002/spe.2409.

[10] I. S. A. Mohamed, "Digital signature in e-commerce security," Middle East Journal for Scientific Publishing (MEJSP), vol. 1, no. 1 , pp. 26-34, 2018

[11] S. A. Ehikioya and A. A. Olukunle, "Formal model of distributed security for electronic commerce transactions systems," International Journal of Networked and Distributed Computing (IJNDC), vol. 7, no. 2, pp. 68-84, 2019, doi: 10.2991/ijndc.k.190326.003.

[12] S. A. Tago, F. H. Chandio, M. S. Chandio, M. S. Abbasi, and H. F. Naqvi, "Conceptual framework for understanding mobile commerce applications," University of Sindh Journal of Information and Communication Technology (USJICT), vol. 1, no. 1, pp. $1-7,2017$

[13] E. Turban, J. Outland, D. King, J. K. Lee, T. P. Liang, and D. C. Turban, "E-Commerce: mechanisms, platforms, and tools," in Electronic Commerce 2018, pp. 41-76, 2018, doi: 10.1007/978-3-319-58715-8_2.

[14] A. Kaya and Ö. Aydin, "E-commerce in Turkey and SAP integrated e-commerce system," International Journal of eBusiness and e-Government Studies, vol. 11, no. 2, pp. 207-225, 2019, doi: 10.34111/ijebeg.20191128.

[15] S. O. Fadiya, E. J. Chukwuemeka, and O. A. Okolobia, "Implementation of e-commerce based on cloud computing using ASP.NET technology," International Journal of Business and Applied Social Science, vol. 2, no. 7, pp. 61-76, 2016.

[16] Sharminakter, "The design and implementation of e-commerce management system," IOSR Journal of Electronics and Communication Engineering (IOSR-JECE), vol. 12, no. 1, pp. 29-36, 2017, doi: 10.9790/2834-1201022936. 
[17] F. Wei and Q. Zhang, "Design and implementation of online shopping system based on B/S Model," MATEC Web of Conferences, vol. 246, 2018, pp. 1-5, doi: 10.1051/matecconf/201824603033.

[18] Y. M. Malgwi and L. Mathias, "Development and implementation of e-commerce system," International Journal of Advanced Research in Computer Science, vol. 9, no. 1, pp. 900-907, 2018, doi: 10.26483/ijarcs.v9i1.5529.

[19] H. S. M. Alsultani and Q. K. Kadhim, "Design and implementation of e-commerce website for shopping," The First International Scientific Conference for E-Applications in the Academic Forum of the University of Diyala Iraq, University of Diyala Iraq, 2018, pp. 1-8.

[20] A. Yunus and M. Masum, "Design and development of an e-commerce system in a rapid organized way," International Journal of Science and Research (IJSR), vol. 9 no. 3, pp. 1368-1375, 2020, doi: 10.21275/SR20325195821.

[21] J. Marques and S. Yelisetty, "An analysis of software requirements specification characteristics in regulated environments," International Journal of Software Engineering and Applications (IJSEA), vol. 10, no. 6, pp. 1-15, 2019, doi: 10.5121/ijsea.2019.10601.

[22] G. Casale et al., "Current and future challenges of software engineering, for services and applications," Procedia Computer Science, vol. 97 no. 3, pp. 34-42, 2016, doi: 10.1016/j.procs.2016.08.278.

[23] S. A. Ehikioya and E. Guillemot, "A critical assessment of the design issues in e-commerce systems development," Engineering Reports published by John Wiley and Sons, Ltd., vol. 2, no. 4, pp. 1-24, 2020, doi: 10.1002/eng2.12155.

[24] A. Nechaev and O. Antipina, "Analysis of the impact of taxation of business entities on the innovative development of the country," European Research Studies Journal, vol. 19, no. 1, pp. 71-83, 2016, doi: 10.35808/ersj/507.

[25] H. Azwar, M. Murtaz, M. Siqque, and S. Rehman, "Intrusion detection insecure network for cybersecurity systems using machine learning and data mining," 2018 IEEE 5th International Conference on Engineering Technologies and Applied Sciences (ICETAS), 2018, pp. 1-9, doi: 10.1109/ICETAS.2018.8629197.

[26] K. Ahmad and M. S. Alam, "E-commerce security through elliptic curve cryptography," International Conference on Information Security and Privacy (ICISP2015), vol. 78, 2016, pp. 867-873, doi: 10.1016/j.procs.2016.05.549.

[27] S. A. Ehikioya and J. Zheng, "Web usage content data logging for discovering user interests," Computing, Information system and Development Informatics Journal (cisdi), vol. 9, no. 2, pp. 43-50, 2018.

[28] H. Rahman and R. Rahmani, "Enabling distributed intelligence assisted future internet of things controller (FITC)," Applied Computing and Informatics, vol. 14, no. 1, pp. 73-87, 2018, doi: 10.1016/j.aci.2017.05.001.

[29] L. Hongyan and L. Zhenyu, "E-commerce consumer behavior information big data mining," International Journal of Database Theory and Application, vol. 9, no. 7, pp. 135-146, 2016, doi: 10.14257/ijdta.2016.9.7.12.

[30] N. Kuruwitaarachchi, P. K. W. Abeygunawardena, L. Rupasingha, and S. W. I. Udara, "A systematic review of security in electronic commerce- threats and frameworks," Global Journal of Computer Science and Technology: E Network, Web and Security, vol. 19 no. 1, pp. 33-39, 2019, doi: 10.34257/GJCSTEVOL19IS1PG33.

[31] S. Ehikioya and A. A. Olukunle, "A formal model of distributed security for electronic commerce transactions systems," International Journal of Networked and Distributed Computing, vol. 7, no. 2, pp. 68-84, April 2019, doi: 10.2991/ijndc.k.190326.003.

[32] A. Farahzadi, P. Shams, J. Rezazadeh, and R. Farahbakhsh, "Middleware technologies for a cloud of things: a survey," Digital Communication Networks, vol. 4, no. 3, pp. 176-188, 2018, doi: 10.1016/j.dcan.2017.04.005.

[33] K. Benmoussa, M. Laaziri, S. Khoulji, K. M. Larbi, and A. E. Yamami, "Enhanced model for ergonomic evaluation of information systems: application to scientific research information system," International Journal of Electrical and Computer Engineering (IJECE), vol. 9, no. 1, pp. 683-694, 2019, doi: 10.11591/ijece.v9i1.pp683-694.

[34] M. Collotta, G. Pau, T. Talty and O. K. Tonguz, "Bluetooth 5: A Concrete Step Forward toward the IoT," in IEEE Communications Magazine, vol. 56, no. 7, pp. 125-131, July 2018, doi: 10.1109/MCOM.2018.1700053.

[35] H. F. Atlam, A. Alenezi, A. Alharthi, R. J. Walters and G. B. Wills, "Integration of cloud computing with internet of things: challenges and open issues," 2017 IEEE International Conference on Internet of Things (iThings) and IEEE Green Computing and Communications (GreenCom) and IEEE Cyber, Physical and Social Computing (CPSCom) and IEEE Smart Data (SmartData), 2017, pp. 670-675, doi: 10.1109/iThings-GreenCom-CPSCom-SmartData.2017.105.

[36] T. Wahyuningrum and K. Mustofa, "A systematic mapping review of software quality measurement: research trends, model, and method," International Journal of Electrical and Computer Engineering (IJECE), vol 7, no 5, pp. 2847-2854, 2017, doi: 10.11591/ijece.v7i5.pp2847-2854.

[37] V. Adat and B. Gupta, "Security in internet of things: issues, challenges, taxonomy, and architecture," Telecommunication Systems, vol. 67, no. 3, pp. 423-441, 2018, doi: 10.1007/s11235-017-0345-9.

[38] K. Angkananon, M. Wald, and P. Ploadaksorn, "Development and testing of a Thai website accessibility evaluation tool," International Journal of Electrical and Computer Engineering (IJECE), vol. 10, no. 5, pp. 4900-4909, 2020, doi: 10.11591/ijece.v10i5.pp4900-4909.

[39] C. J. Nwoye, "Design and development of an e-commerce security using RSA cryptosystem," International Journal of Innovative Research in Information Security (IJIRIS), vol. 6, no. 2, pp. 5-11, 2015.

[40] Z. Wang, Y. Zhao, and G. Zhong, "Public-key applications in e-commerce," IOP Conference Series: Journal of Physics: Conference Series, 2019, pp. 1-6, doi: 10.1088/1742-6596/1213/4/042083.

[41] V. F. D. Santos, L. R. Sabino, G. M. Morais, "E-commerce: a short history follow-up on possible trends," International Journal of Business Administration, vol. 8, no. 7, pp. 130-138, 2017, doi: 10.5430/ijba.v8n7p130

[42] S. M. F. Mahmood, "E-commerce, online shopping, and customer satisfaction: an empirical study on e-commerce system in Dhaka," International Journal of Entrepreneurship and Development Studies, vol. 4, no. 3, pp. 323-338, 2016.

[43] E. G. Nihad, K. Mohamed, and E.-N. E. Mokhtar, "Designing and modeling of a multi-agent adaptive learning system (MAALS) using incremental hybrid case-based reasoning (IHCBR)," International Journal of Electrical and Computer Engineering (IJECE), vol. 10, no. 2, pp. 1980-1992, 2020, doi: 10.11591/ijece.v10i2.pp1980-1992.

[44] E. Vollset, "E-commerce apps: the 10 most common consumer complaints," Octopus Mercantile Research Report, 2018.

[45] M. A. Hassan, Z. Shukur, and M. Kamrul Hasan, "An efficient secure electronic payment system for e-commerce," Computers MDPI, vol. 9, no. 3, pp. 1-13, 2020, doi: 10.3390/computers9030066.

[46] C. Yang, Y. Chen, S. Chen and S. Wu, "A reliable e-commerce business model using blockchain based product grading system," 2019 IEEE 4th International Conference on Big Data Analytics (ICBDA), 2019, pp. 341-344, doi: 10.1109/ICBDA.2019.8713204.

[47] Z. Qin, "E-commerce Supporting Technologies," in Introduction to E-commerce $1^{\text {st }}$ edition, Tsinghua University Press, Beijing and Springer-Verlag GmbH Berlin Heidelberg, Ch. 2, sec. 2,3, 4, pp. 77-168, 2009. [Online]. Available: https://www.academia.edu/6760422/Introduction_to_E_commerce 


\section{BIOGRAPHIES OF AUTHORS}

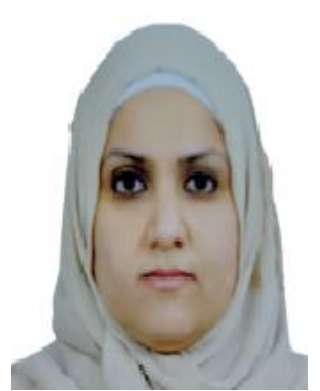

Farah Tawfiq Abdul Hussein (D) Id SC P Awarded her B.Sc. and her M.Sc. degree from the University of Technology Baghdad Iraq in 2020 and 2008 respectively. She worked as a member of the Examination Committee at the Training and Laboratory Center for the years 2002-2004, director of the Scientific Affairs Division of the Office of the Scientific Assistant in the Presidency of the University of Technology for the years 2011-2012, the decision of the University Committee for Scientific Affairs for the years 2011-2012, the decision of the university committee for hazardous chemicals and toxic substances for the years 2011-2012, director of the Scientific Products Division of the Assistant to Scientific Office of the President of the University 2014, member of the Examination Committee of the Multimedia Branch for the years 2016-2018, member of the Scientific Committee of the Multimedia Branch for the years 2016 -2018, member of the Educational Guidance Committee 2016, member of the National Quality Classification Committee for the year 2018. She has taught in the computer science department at the University of Technology since 2010 till now. She got Promotion to the rank of lecturer in 2019. She started her Ph.D. studies in 2019 and recently in the research stage. She published 3 papers. Her research interest includes computer security, image processing, and algorithms analysis. She can be contacted at email: Farah.T.Alhilo@uotechnology.edu.iq.

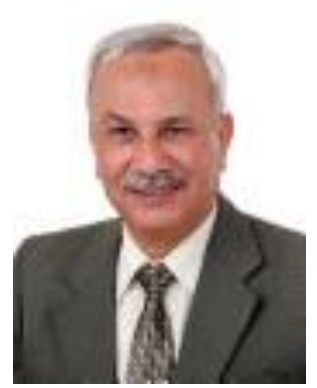

Abdul Monem S. Rahma (D) SII SC P University of Technology, Baghdad, Iraq. Awarded his M.Sc. degree from Brunel University and his Ph.D. from Loughborough University of Technology, the UK in 1982 and 1984, respectively. He taught at the University of Baghdad, Department of Computer Science and the Military College of Engineering, Computer Engineering Department from 1986 to 2003, and works as a Professor at the University of Technology Department of Computer Science. He was Deputy Dean in the Department of Computer Science from 2005 to 2013. From 2013 to 2015, he was the Dean of the Department of Computer Science, University of Technology. He published 160 papers and four books in the field of computer science and supervised 34 Ph.D. and 65 M.Sc. students. His research interests include computer graphics image processing, biometrics, and computer security. He can be contacted at email: 110003@uotechnology.edu.iq.

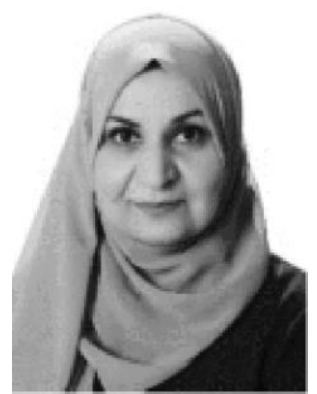

Hala Bahjat Abdul Wahab (D) IS SC P (F'51) This author became a Reviewer (R) of IEEE in 2010. Was born in Basrah, Iraq in 1969. She received a B.S. degree in 1990 in computer science, Basrah University, M.S. degrees in 2001 in computer science, Technology university, and finally the Ph.D. degree in 2006 in computer science security from the department of computer science, University of Technology, Baghdad, Iraq. She received a professor degree in 2018 from the technology university. From 1991 to 1995, Dr. Hala was a lecturer assistant in the computer science department at the Basrah University, Iraq. From 1995 to 2020, Dr. Hala was a lecturer in the computer science department at the Technology University, Iraq. She received the Assistant professor degree in 2006 and the professor degree in 2018 from the technology university. Prof. Hala is the author of more than 65 articles. Prof. Hala's research interests include Information and Network Security. Prof. Hala is a co-author in the "PGP Protocols and its Applications" book in IN TECH 2012. She can be contacted at email: hala_bahjat@yahoo.com. 